\title{
Pengaruh Organizational Learning, Organizational Commitment dan Job Satisfaction Terhadap Employee Performance di Jakarta
}

\author{
Rahadian Mohamad dan M. Tony Nawawi \\ Program Studi S1Manajemen Fakultas Ekonomi \& Bisnis \\ Universitas Tarumanagara \\ Email : rmohamad0328@gmail.com
}

\begin{abstract}
This research is focusing on three variables of Organizational Learning, Organizational Commitment and Job Satisfaction, and its effects on Employee Performance. Total of 90 employees who work in General Service Division of Bank BTPN Jakarta are selected as samples for this research. The methods used are Quantitative Research, in which all the samples are required to answer an online questionnaire that the researcher sent. Then, the results of the questionnaire were analyzed with PLS-SEM methods using analytical software SmartPLS 3. The results showed that (1) Organizational Learning has a positive and significant effect on Employee Performance, (2) Organizational Commitment has a positive and significant effect on Employee Performance, and (3) Job Satisfaction has a positive and significant effect on Employee Performance.
\end{abstract}

Abstrak: Dalam penelitian ini berfokus pada tiga variabel, yaitu Organizational Learning, Organizational Commitment dan Job Satisfaction, dan pengaruhnya terhadap Employee Performance. Penelitian ini dilakukan terhadap 90 responden yang bekerja pada divisi General Service di Kantor Pusat Bank BTPN Jakarta. Metode penelitian yang digunakan adalah metode kuantitatif, dimana responden akan menjawab kuesioner berbasis online yang dikirimkan oleh peneliti. Kemudian data yang diperoleh diolah dengan metode PLS-SEM menggunakan software pengolahan data SmartPLS 3. Hasil penelitian menunjukkan bahwa (1) Organizational Learning mempunyai pengaruh yang positif dan signifikan terhadap Employee Performance, (2) Organizational Commitment mempunyai pengaruh yang positif dan signifikan terhadap Employee Performance, dan (3) Job Satisfaction mempunyai pengaruh yang positif dan signifikan terhadap Employee Performance.

Keywords: Organizational Learning, Organizational Commitment, Job Satisfaction, Employee Performance

\section{LATAR BELAKANG}

Digaungkan nya revolusi industri 4.0 dan penggunaan teknologi dalam berbagai aktivitas perekonomian, akan memberikan peluang dan tantangan tersendiri bagi hampir seluruh perusahaan. Penggunaan kecerdasan buatan atau Artificial Intelligence dalam sebuah perusahaan dapat meningkatkan produktivitas, efektifitas dan efisiensi serta memberikan kemudahan bagi konsumen. Namun dalam berbagai keunggulan tersebut akan memunculkan ancaman bagi tenaga kerja, dalam sebuah penelitian yang dilakukan McKinsey, yang dimuat dalam Rencana Pembangunan Jangka Menengah Nasional 2020-2024 oleh Kementerian PPN/Bappenas (2019), bahwa setidaknya 60 persen jabatan pekerjaan akan hilang dan tergantikan oleh tenaga mesin, sementara di Indonesia sendiri diperkirakan akan terjadi sekitar 51,8 persen. Setiap perusahaan akan berlomba-lomba dalam menciptakan keunggulan kompetitif mereka untuk dapat terus menghadapi persaingan pasar, menghasilkan keuntungan yang sebesar-besarnya dengan biaya serendah mungkin, terutama dengan inflasi harga bahan 
baku dari tahun ke tahun dan atau tingkat upah yang akan meningkat seiring waktu. Untuk itu, perusahaan perlu menyiapkan strategi yang tepat, seperti dengan penggunaan analisis SWOT (strength, weakness, opportunity, threat), dalam pembuatan kebijakan dan sistem manajemen sumber daya manusia, terutama untuk menghadapi perubahan-perubahan yang mungkin terjadi di dalam perusahaan maupun berbagai ancaman dari luar di masa mendatang. Dessler (2011) menyatakan pentingnya menghubungkan strategi sumber daya manusia dengan strategi perusahaan. Dengan pengelolaan yang baik oleh manajemen, maka karyawan akan merasa termotivasi serta bekerja keras untuk membantu perusahaan mencapai tujuan-tujuan yang ditetapkan pemimpin perusahaan tersebut, salah satunya dengan memberikan perhatian penuh pada kinerja karyawan.

Employee Performance atau kinerja karyawan merupakan hasil baik secara finansial atau non-finansial oleh karyawan serta mempunyai hubungan terhadap kinerja dan kesuksesan organisasi (Anitha, 2013). Kinerja karyawan merupakan tingkat keberhasilan seseorang dalam menyelesaikan tugas dan tanggung jawabnya dibandingkan dengan standar pencapaian yang ditetapkan perusahaan selama periode tertentu. Manajemen kinerja yang baik akan memastikan pengelolaan kinerja karyawan yang juga baik. Šikýř (2011) menyatakan Kinerja karyawan yang baik akan memungkinkan perusahaan memproduksi dan mendistribusikan produk dan jasa yang diminta.

Elu (2003) mengemukakan perusahaan yang mengaplikasikan pembelajaran organisasi, karyawan akan saling menilai dan meminta feedback, tertantang dengan cara kerja baru dan terlibat dalam pendekatan sistem yang komprehensif. Pembelajaran yang dilakukan secara kontinu akan membuat perusahaan secara terus menerus memperbarui informasi yang telah mereka proses sebelumnya, sehingga perusahaan akan mampu beradaptasi terhadap permasalahan yang dapat terjadi di kemudian hari, seperti dalam proses pengambilan keputusan dimana karyawan atau manajer harus melakukannya secara spontan, atau mendukung berbagai inovasi oleh karyawan yang dapat dijadikan perusahaan sebagai produk mereka di masa depan. Penelitian Khandekar dan Sharma (2006) mengemukakan adanya hubungan positif antara organizational learning dengan kinerja karyawan.

Saranya (2014) menggambarkan kepuasan kerja atau job satisfaction sebagai sebuah rasa puas yang terpenuhi oleh pekerjaan yang dia miliki. Seorang karyawan yang merasa nyaman dan termotivasi dengan tanggung jawab yang ia miliki, perasaan dihargai oleh rekan kerja, serta penghargaan baik secara finansial maupun non finansial yang diberikan perusahaan akan memberi timbal balik yang positif kepada perusahaan. Dengan terpenuhinya faktorfaktor tersebut, secara emosional karyawan akan merasa terpuaskan terhadap pekerjaan yang mereka miliki, dan karyawan yang mempunyai kepuasan kerja yang baik akan menghasilkan kinerja yang lebih tinggi (Hendri, 2019).

Dalam penelitian oleh Pool dan Pool (2007) komitmen organisasi atau organizational commitment menggambarkan seberapa erat hubungan yang dimiliki oleh seseorang kepada sebuah organisasi serta berkomitmen kepada tujuan-tujuan organisasi. Lebih lanjut dijelaskan bahwa sikap kerja merupakan hal yang penting karena karyawan yang berkomitmen akan bekerja keras untuk mencapai tujuan-tujuan organisasi. Penelitian dari Rashid, Sambasivan dan Johari (2003) menunjukkan bahwa budaya kerja dan organizational commitment mempunyai pengaruh yang positif terhadap kinerja karyawan. Karyawan yang menunjukkan komitmen tersebut mempunyai keinginan yang besar untuk tetap bekerja di perusahaan tempatnya bekerja dan akan mampu memberikan hasil kerja yang positif serta menunjukkan keinginan yang kuat untuk bekerja dalam waktu yang lama dalam perusahaan.

Dari latar belakang yang telah dijabarkan diatas, penulis bermaksud (1) untuk mengetahui pengaruh organizational learning terhadap employee performance, (2) Untuk mengetahui pengaruh organizational commitment terhadap employee performance dan (3) Untuk mengetahui pengaruh job satisfaction terhadap employee performance. Dengan adanya 
penelitian ini diharapkan akan memberi manfaat dalam menghadapi masalah mengenai kinerja karyawan bagi berbagai perusahaan dan penunjang penelitian lain yang selaras dengan penelitian ini.

\section{KAJIAN TEORI}

Organizational learning dalam Elshanti (2017) merupakan kegiatan yang diantaranya mendapatkan dan mengembangkan ilmu yang berguna bagi organisasi, meningkatkan kapasitas organisasi dalam pengambilan keputusan yang produktif, dan sebagai sarana pendeteksi dan perbaikan kesalahan. Sementara Gunbayi dan Sorm (2019) mengartikannya sebagai peningkatan kemampuan dan produktivitas yang didapat melalui pengembangan yang berkelanjutan di dalam organisasi. Lalu dalam penelitian Hendri (2019) pembelajaran organisasi merupakan pandangan kolektif yang terbangun dalam sebuah organisasi, atau pemrograman mental kolektif yang dikembangkan di dalam organisasi pembelajar atau komunitas pembelajaran.

Organizational commitment dijelaskan oleh Robbins dan Coulter (2011) yaitu sejauh mana seorang karyawan mengaitkan diri mereka dengan organisasi dan tujuan-tujuannya, serta mempunyai keinginan untuk mempertahankan jabatannya didalam organisasi tersebut. Sementara dalam penelitian Einolander (2015) Komitmen organisasional adalah seberapa jauh seseorang menganggap diri mereka sebagai seseorang yang berorganisasi. Penjelasan lebih rinci terdapat dalam penelitian Limpanitgul et al. (2017) dimana komitmen organisasional terbagi atas tiga hal yaitu affective, continuance dan normative, dimana komitmen affective merupakan sebuah perasaan keterikatan kepada perusahaan, continuance merupakan kesadaran terhadap kerugian yang didapat jika meninggalkan perusahaan, dan normative adalah rasa kewajiban untuk terus bekerja dalam perusahaan tersebut.

Dalam penelitian Yilmaz, Celebi dan Cakmak (2013) dijelaskan bahwa job satisfaction atau kepuasan kerja merupakan perasaan yang dimiliki seseorang terhadap pekerjaan dan beberapa aspek lain dalam pekerjaan mereka. Sementara itu Singh (2013) mendefinisikan kepuasan kerja sebagai rasa puas seseorang atau kondisi emosional yang positif, yang dihasilkan dari penilaian terhadap pekerjaan yang dimiliki atau pengalaman yang didapat dari pekerjaan tersebut. Lalu Robbins dan Coulter (2011) mendefiniskan job satisfaction sebagai sikap umum seseorang terhadap pekerjaannya, dimana seseorang dengan kepuasan kerja yang tinggi mempunyai sikap positif terhadap pekerjaannya dan sebaliknya.

Dalam Gibson et al. (2011) kinerja atau performance merupakan hasil suatu pekerjaan yang berhubungan dengan tujuan organisasi seperti kualitas, efisiensi, dan karakteristik keefektifan yang lain. Lalu Colquitt et al. (2014) menjelaskan kinerja sebagai sebuah nilai dari berbagai perilaku karyawan yang berkontribusi terhadap pencapaian tujuan organisasi baik positif atau negatif. Sementara Audenaert et al. (2016) mendefinisikan kinerja sebagai suatu kuantitas dan kualitas kontribusi karyawan terhadap tujuan organisasi baik secara langsung maupun tidak langsung.

Kaitan antara organizational learning dengan employee performance dikemukakan oleh Oh (2018) dimana penelitian ini dimaksudkan untuk menampilkan bagaimana perolehan dan pemindahan pengetahuan mempengaruhi kinerja organisasi. Penemuan dari penelitian ini menunjukkan bahwa terdapat hubungan yang positif antara organizational learning terhadap kinerja organisasi. Selain itu penelitian Jain dan Moreno (2014) hubungan antara organizational learning terhadap kinerja perusahaan dan knowledge managament. Hasilnya seluruh faktor dari organizational learning memberi pengaruh positif terhadap kinerja perusahaan. Penelitian oleh Pham dan Hoang (2019) bertujuan untuk mengetahui hubungan antara organizational learning capability dengan kinerja bisnis perusahaan-perusahaan di 
Vietnam. Hasil dari penelitian tersebut menunjukkan bahwa organizational learning capability mempunyai pengaruh yang positif terhadap kinerja bisnis.

Penelitian Hendri (2019) dilakukan terhadap karyawan yang bekerja di PT. Perkebunan Nusantara XIII di Kalimantan Barat. Dalam penelitian tersebut diperlihatkan bahwa terdapat hubungan yang positif antara organizational commitment dengan employee performance. Lalu dalam penelitian Franco dan Franco (2017) bertujuan untuk mengetahui apakah terdapat hubungan antara organizational commitment di perusahaan keluarga skala kecil dan menengah, terhadap kinerja karyawan. Hasil dari penelitian tersebut menunjukkan bahwa ada hubungan positif antara affective commitment dengan performance, yang dapat dikarenakan karyawan yang mempunyai hubungan emosional dengan perusahaan dimana mereka bekerja, sesuai dengan definisi affective commitment itu sendiri. Selain itu penelitian Suliman dan Kathairi (2013) bertujuan untuk menguji hubungan antara organizational justice, organizational commitment, dan job performance terhadap karyawan penuh waktu di tiga organisasi pemerintah di Abu Dhabi. Penelitian tersebut menunjukkan bahwa terdapat hubungan yang positif antara organizational commitment dengan employee performance.

Nawawi (2015) melakukan penelitian dengan tujuan menganalisa hubungan antara job satisfaction dan motivasi terhadap employee performance terhadap karyawan outsourcing yang ditempatkan di Kampus II Universitas Tarumanagara, Jakarta. Dari penelitian ini dapat dibuktikan bahwa terdapat hubungan yang positif antara job satisfaction dengan employee performance. Lalu Penelitian oleh Siengthai dan Pila-Ngarm (2015) bertujuan untuk membahas dampak dari job redesign dan job satisfaction terhadap employee performance. Hasil dari penelitian menunjukkan terdapat hubungan yang positif dan signifikan antara job satisfaction dan employee performance. Selain itu penelitian Hendri (2019) juga bertujuan untuk menganalisa hubungan antara job satisfaction dengan employee performance. Dalam penelitian tersebut diperlihatkan bahwa terdapat hubungan yang positif antara job satisfaction dengan employee performance.

Dari kajian diatas, model kerangka pemikiran adalah sebagai berikut:

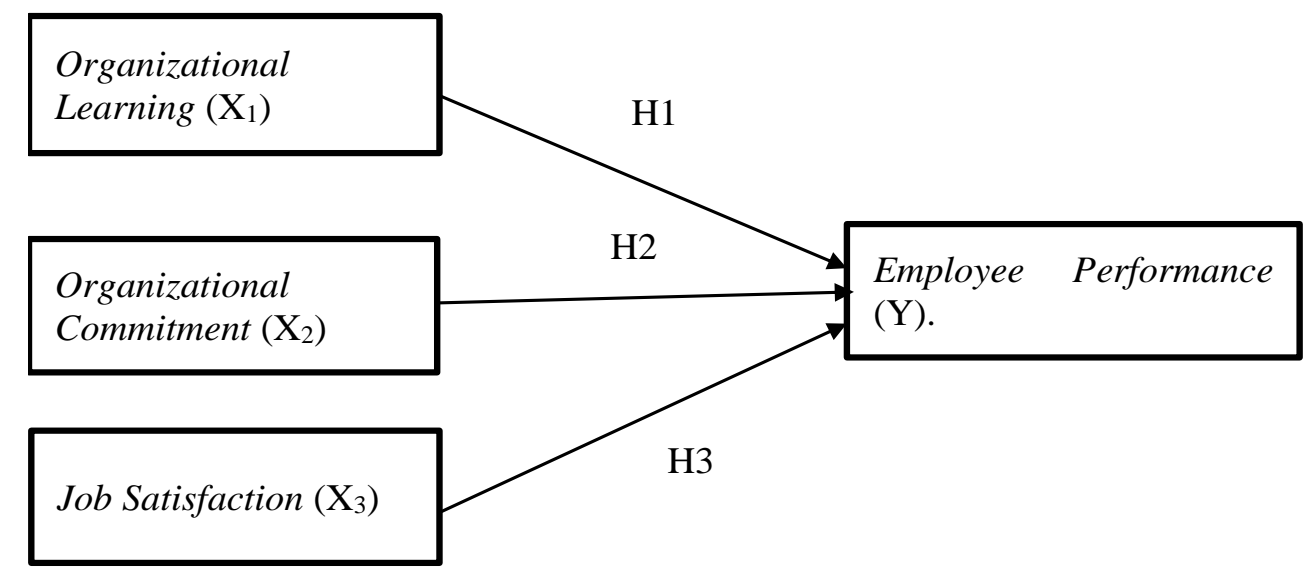

Gambar 1. Model Penelitian

Berdasarkan dengan kerangka pemikiran yang telah digambarkan diatas, maka perumusan hipotesis yang diajukan dalam penelitian ini adalah, H1: Terdapat pengaruh positif dan signifikan Organizational Learning terhadap employee performance, $\mathrm{H} 2$ : Terdapat pengaruh positif dan signifikan Organizational Commitment terhadap employee performance dan terakhir H3: Terdapat pengaruh positif dan signifikan Job Satisfaction terhadap employee performance. 


\section{METODOLOGI}

Penelitian ini merupakan penelitian kausalitas, yaitu suatu desain penelitian yang disusun untuk meneliti kemungkinan adanya hubungan sebab-akibat antar variabel (Sanusi, 2011), dan jenis penelitian yang digunakan adalah jenis penelitian kuantitatif. Penelitian ini dilaksanakan dengan menggunakan kuesioner sebagai instrumen pengumpulan data, dan kuesioner tersebut disebar secara online kepada seluruh responden, dimana responden yang terpilih merupakan seluruh karyawan pada divisi general service Bank BTPN Jakarta dan total responden berjumlah 90 orang.

Dalam penelitian ini, variabel organizational learning (X1) mempunyai 9 indikator yang bersumber dari Garvin (1993), organizational commitment (X2) mempunyai 9 indikator yang bersumber dari Allen dan Meyer (1990), job satisfaction (X3) mempunyai mempunyai 11 indikator yang bersumber dari Colquitt et al. (2014), dan employee performance (Y) mempunyai 10 indikator yang bersumber dari Suliman (2001).

Penelitian ini menggunakan teknik analisis data PLS-SEM (partial least squares structural equation modeling), dengan perangkat lunak SmartPLS (v3.3.2) sebagai alat penganalisis data, yang digunakan untuk melakukan uji statistik yang terdiri dari uji validitas konvergen, uji validitas diskriminan dan uji reliabilitas untuk menguji validitas dan reliabilitas kuesioner, lalu untuk uji analisis data menggunakan pengujian seperti Coefficient of Determination $\left(R^{2}\right)$, Predictive Relevance $\left(Q^{2}\right)$, Goodness of Fit $(G o F)$ dan Hypothesis Testing (Ghozali dan Latan, 2015), namun dalam penelitian ini tidak akan dilakukan pengujian Goodness of Fit karena tidak dapat diaplikasikan pada teknik analisis PLS-SEM (Ringle et al., 2014; Hair et al., 2019).

\section{HASIL UJI STATISTIK}

Merujuk tabel 1, hasil uji validitas konvergen yang dimana koefisien AVE menunjukkan nilai diatas 0,5. Maka dari itu, variabel-variabel diatas memenuhi syarat analisis validitas konvergen. Lalu hasil uji validitas diskriminan dengan metode HTMT, yang tertera pada tabel 2, dimana seluruh variabel mempunyai nilai lebih rendah dari 0,9 , sehingga memenuhi syarat validitas diskriminan. Dan Pada Hasil uji reliabilitas yang tertera tabel 3, terlihat bahwa pada hasil dari rho_A menunjukkan angka yang baik dan tidak melebihi angka 0,95. maka dari itu seluruh variabel dalam penelitian ini reliable atau dapat diandalkan.

Tabel 1. Hasil analisis AVE

\begin{tabular}{|c|c|}
\hline Variabel & Nilai AVE \\
\hline Organizational Learning $(X 1)$ & 0,511 \\
\hline Organizational Commitment $(X 2)$ & 0,514 \\
\hline Job Satisfaction $(X 3)$ & 0,516 \\
\hline Employee Performance $(Y)$ & 0,509 \\
\hline
\end{tabular}

Sumber: SmartPLS

Tabel 2. Hasil analisis HTMT

\begin{tabular}{|c|c|}
\hline Variabel & $\begin{array}{l}\text { Nilai } \\
\text { HTMT }\end{array}$ \\
\hline Organizational Learning (X1) - Organizational Commitment (X2) & 0,487 \\
\hline Organizational Learning (X1) - Job Satisfaction $(X 3)$ & 0,530 \\
\hline Organizational Commitment (X2) - Job Satisfaction (X3) & 0,864 \\
\hline Employee Performance (Y) - Organizational Learning (X1) & 0,696 \\
\hline Employee Performance (Y) - Organizational Commitment (X2) & 0,668 \\
\hline
\end{tabular}




\section{Employee Performance (Y) - Job Satisfaction (X3) \\ 0,710}

Sumber: SmartPLS

Tabel 3. Hasil analisis rho_A

\begin{tabular}{|c|c|}
\hline Variabel & Nilai rho_A \\
\hline Organizational Learning $(X 1)$ & 0,770 \\
\hline Organizational Commitment $(X 2)$ & 0,837 \\
\hline Job Satisfaction $(X 3)$ & 0,713 \\
\hline Employee Performance $(Y)$ & 0,784 \\
\hline
\end{tabular}

Sumber: SmartPLS

Setelah pengujian validitas dan reliablitas dilakukan maka penelitian masuk pada pengujian analisis data pertama yaitu uji koefisien determinasi $R^{2}$. Namun sebelumnya lebih dahulu dilakukan uji Kolinearitas yang ditujukan pada tabel 4, dimana tidak ada variabelvariabel yang saling kolinear. Sementara itu pada penelitian ini didapat nilai $\mathrm{R}^{2}$ sebesar 0,494 , yang berarti bahwa employee performance dijelaskan oleh variabel-variabel independen pada penelitian ini sebesar 49,4\%, sementara sisanya dijelaskan oleh variabel independen lain yang tidak dianalisis dalam model penelitian ini.

Tabel 4. Hasil Uji VIF

\begin{tabular}{|c|c|c|}
\hline Variabel & Nilai VIF & Keterangan \\
\hline Organizational Learning (X1) & 1,197 & Tidak Ada Kolinearitas \\
\hline Organizational Commitment (X2) & 1,786 & Tidak Ada Kolinearitas \\
\hline Job Satisfaction (X3) & 1,755 & Tidak Ada Kolinearitas \\
\hline
\end{tabular}

Sumber: SmartPLS

Tabel 5. Hasil Uji Predictive Relevance $\left(\mathrm{Q}^{2}\right)$

\begin{tabular}{|c|c|c|}
\hline Variabel & Nilai $\mathrm{Q}^{2}$ & Keterangan \\
\hline Organizational Learning $(\mathrm{X} 1)$ & 0,259 & $\mathrm{Q}^{2}>0$ \\
\hline Organizational Commitment $(\mathrm{X} 2)$ & 0,319 & $\mathrm{Q}^{2}>0$ \\
\hline Job Satisfaction $(\mathrm{X} 3)$ & 0,198 & $\mathrm{Q}^{2}>0$ \\
\hline Employee Performance $(\mathrm{Y})$ & 0,265 & $\mathrm{Q}^{2}>0$ \\
\hline
\end{tabular}

Sumber: SmartPLS

Selanjutnya pada Uji Predictive Relevance $\left(\mathrm{Q}^{2}\right)$ dengan metode blindfolding untuk menguji keakuratan model penelitian dan nilai $\mathrm{Q}^{2}$ menunjukkan hasil diatas 0 sehingga dapat dianggap model penelitian ini akurat.

Terakhir pengujian hipotesis atau Hypothesis Testing dilaksanakan tiga pengujian yaitu uji path coeffiecient, significance dan effect size $\left(f^{2}\right)$.

Tabel 6. Hasil Uji Path Coefficient

\begin{tabular}{|c|c|c|}
\hline Variabel (terhadap variabel dependen) & Koefisien & Keterangan \\
\hline $\begin{array}{c}\text { Organizational Learning (X1) - Employee } \\
\text { Performance }(Y)\end{array}$ & 0,395 & Positif \\
\hline $\begin{array}{c}\text { Organizational Commitment }(\mathrm{X} 2) \text { - Employee } \\
\text { Performance }(Y)\end{array}$ & 0,266 & Positif \\
\hline Job Satisfaction (X3) - Employee Performance $(Y)$ & 0,222 & Positif \\
\hline
\end{tabular}

Sumber: SmartPLS 
Tabel 7. Hasil Significance Test

\begin{tabular}{|c|c|c|c|}
\hline Variabel (terhadap variabel dependen) & $t$-value & $P$-values & Keterangan \\
\hline $\begin{array}{c}\text { Organizational Learning }(\mathrm{X} 1)- \\
\text { Employee Performance }(Y)\end{array}$ & 4,786 & 0,000 & $\begin{array}{l}\text { Hipotesis } \\
\text { Diterima }\end{array}$ \\
\hline $\begin{array}{c}\text { Organizational Commitment }(\mathrm{X} 2)- \\
\text { Employee Performance }(Y)\end{array}$ & 2,917 & 0,004 & $\begin{array}{l}\text { Hipotesis } \\
\text { Diterima }\end{array}$ \\
\hline $\begin{array}{c}\text { Job Satisfaction }(\mathrm{X} 3)-\text { Employee } \\
\text { Performance }(Y)\end{array}$ & 2,353 & 0,019 & $\begin{array}{l}\text { Hipotesis } \\
\text { Diterima }\end{array}$ \\
\hline
\end{tabular}

Sumber: SmartPLS

Tabel 8. Hasil Uji Effect Size

\begin{tabular}{|c|c|}
\hline Variabel (terhadap variabel dependen) & Nilai $f^{2}$ \\
\hline Organizational Learning (X1) - Employee Performance $(Y)$ & 0,258 \\
\hline Organizational Commitment (X2) - Employee Performance $(Y)$ & 0,079 \\
\hline Job Satisfaction (X3) - Employee Performance $(Y)$ & 0,056 \\
\hline
\end{tabular}

Sumber: SmartPLS

Terlihat bahwa pada tabel 6 dan 7, hubungan antara variabel independen dan dependen pada penelitian ini menunjukkan hubungan yang positif dan signifikan pada ketiga hipotesis sehingga seluruh hipotesis dapat diterima.

Sementara pada tabel 8 merupakan pengujian untuk mengetahui dampak terhadap nilai $\mathrm{R}^{2}$ jika suatu variabel dihilangkan dari model penelitian dimana nilai $\mathrm{f}^{2}$ sebesar 0,02 keatas, dampak menengah sebesar 0,15 keatas dan dampak tinggi sebesar 0,35 keatas. Pada tabel 8, dapat diartikan bahwa jika variabel Organizational Learning dihilangkan maka akan memberi dampak menengah, jika variabel Organizational Commitment dihilangkan akan memberi dampak kecil dan jika variabel Job Satisfaction dihilangkan akan memberi dampak kecil.

\section{DISKUSI}

Dalam penelitian ini, hipotesis pertama (H1) adalah adanya pengaruh positif dan signifikan organizational learning terhadap employee performance, yaitu bahwa karyawan dengan yang memperoleh pengetahuan dan keterampilan dalam pekerjaannya maka akan mempengaruhi kinerja karyawan tersebut. Hasil ini membuktikan bahwa penelitian ini sejalan dengan penelitian Oh (2018) dimana organizational learning mempengaruhi kinerja dalam organisasi. Jain dan Moreno (2014) juga mengemukakan adanya hubungan yang positif antara organizational learning terhadap kinerja perusahaan. Selain itu, penelitian Pham dan Hoang (2019) menunjukkan adanya hubungan positif antara organizational learning capabilities dengan kinerja bisnis.

Selanjutnya hipotesis kedua $(\mathrm{H} 2)$ adalah adanya pengaruh positif dan signifikan organizational commitment dengan employee performance, yaitu organisasi yang dimana karyawannya memiliki komitmen yang tinggi cenderung akan menunjukkan kinerja yang tinggi. Hasil ini membuktikan bahwa penelitian ini sejalan dengan penelitian Hendri (2019) dimana terdapat hubungan yang positif antara organizational commitment dengan employee performance. Franco dan Franco (2017) juga mengemukakan adanya hubungan yang positif antara affective commitment terhadap kinerja. Selain itu, penelitian Suliman dan Kathairi (2013) menunjukkan terdapat hubungan yang positif antara organizational commitment dengan employee performance.

Terakhir pada hipotesis ketiga (H3) adalah adanya pengaruh positif dan signifikan job satisfaction dengan employee performance, yaitu dimana karyawan yang mempunyai 
kepuasan kerja yang baik akan menghasilkan kinerja yang lebih tinggi. Hasil ini membuktikan bahwa penelitian ini sejalan dengan penelitian Nawawi (2015) yang dibuktikan bahwa terdapat hubungan yang positif antara job satisfaction dengan employee performance. Siengthai dan Pila-Ngarm (2015) juga mengemukakan terdapat hubungan yang positif dan signifikan antara job satisfaction dan employee performance. Selain itu, penelitian Hendri (2019) memperlihatkan bahwa terdapat hubungan yang positif antara job satisfaction dengan employee performance.

\section{PENUTUP}

Mengacu pada hasil dari penelitian, dapat dilihat bahwa pelaksanaan organizational learning membantu karyawan dalam mencapai kinerja yang diharapkan suatu perusahaan, seperti memberi pelatihan dan pengembangan karyawan, membangun suatu sistem penyebaran informasi, serta memberikan kesempatan karyawan untuk berinovasi dan menciptakan solusi baru dalam menghadapi perubahan-perubahan yang terjadi. Selanjutnya, komitmen yang dimiliki karyawan terhadap perusahaan berpengaruh pada kinerja mereka. Karyawan yang memiliki komitmen yang tinggi akan memberikan hasil yang baik dalam pekerjaannya. Komitmen yang tinggi dapat dilihat pada beberapa hal seperti rendahnya absensi dan keterlambatan. Komitmen karyawan dapat dibangun melalui beberapa hal, seperti penanaman budaya organisasi, hubungan baik karyawan dengan perusahaan, dan citra baik perusahaan di mata karyawan. Terakhir, kinerja karyawan juga dipengaruhi oleh seberapa puas mereka dengan kondisi mereka di dalam perusahaan, baik melalui pemberian upah dan gaji yang tepat, sampai pada pekerjaan mereka itu sendiri. Untuk membangun kepuasan pada karyawan, dapat dilihat dari beberapa hal, seperti sistem apresiasi baik secara finansial seperti gaji atau benefit seperti asuransi atau jaminan, dan non-finansial seperti penghargaan atau pujian dari atasan, lalu sistem promosi berbasis kinerja, serta dapat dengan memberikan tugas yang cukup menantang karyawan untuk diselesaikan.

Terkait keterbatasan dan saran untuk penelitian mendatang, penelitian ini dilakukan menggunakan variabel-variabel yang spesifik yang dipilih oleh peneliti, lalu penelitian juga dilakukan hanya pada salah satu divisi perusahaan untuk menggambarkan kondisi umum perusahaan tersebut, dan terdapat kemungkinan terjadi hasil yang berbeda dari hasil pada penelitian ini. Maka diharapkan untuk penelitian yang mendatang, penelitian tersebut dapat dilakukan menyeluruh pada satu perusahaan jika memungkinkan, dapat mengganti atau menambah variabel selain pada penelitian ini atau merubah kerangka pemikiran, sehingga akan memberi hasil yang beragam demi menemukan suatu cara lain dalam meningkatkan kinerja karyawan, baik pada suatu perusahaan atau instansi lain.

\section{DAFTAR PUSTAKA}

Allen, N. J., \& Meyer, J. P. (1990). The measurement and antecedents of affective, continuance and normative commitment to the organization. Journal of Occupational Psychology, 63, 1-18.

Anitha, J., (2014). Determinants of employee engagement and their impact on employee performance. International Journal of Productivity and Performance Management, 63(3), 308-323.

Audenaert, M., Decramer, A., Lange, T., \& Vanderstraeten, A. (2016). Setting high expectations is not enough: Linkages between expectation climate strength, trust, and employee performance. International Journal of Manpower, 37(6), 1024-1041. 
Colquitt, J. A., Lepine, J. A., \& Wesson, M. J. (2014). Organizational Behavior: Improving Performance and Commitment in the Workplace (4th ed.). New York: McGraw-Hill Education.

Dessler, G. (2012). Human Resource Management (13th ed.). New Jersey: Pearson Education.

Einolander, J. (2015). Evaluating Organizational Commitment in Support of Organizational Leadership. Procedia Manufacturing, 3(Ahfe), 668-673.

Elshanti, M. (2017). Transformational Leadership Style and Organizational Learning: The Mediate Effect of Organizational Culture. International Journal of Economics \& Management Sciences, 06(06).

Elu, W. B. (2003). Manajemen strategis berbasis Kompetensi. Jurnal Ilmiah Administrasi Publik, 4, 4-21.

Franco, M., \& Franco, S. (2017). Organizational commitment in family SMEs and its influence on contextual performance. Team Performance Management, 23(7-8), 364384.

Garvin, D. A. (1993). Building a learning organization. Harvard Business Review, 71(4), 7891.

Ghozali, I., \& Latan, H. (2015). Partial Least Square, Konsep Teknik Dan Aplikasi Dengan Menggunakan Smart PLS 3.0. Untuk Penelitian Empiris. Semarang: Badan Penerbit Universitas Diponegoro.

Gibson, J. L., Ivancevich, J. M., Donnely Jr., J. H., \& Konopaske, R. (2011). Organizations: Behavior, Structure, Processes (14th ed.). New York: McGraw-Hill.

Gunbayi, Ii., \& Sorm, S. (2018). Paradigms In Guiding Management Approaches And Theories: Classical, Neoclassical, Modern And Postmodern Theories. International Journal on New Trends in Education and Their Implications, 10(2), 39-55.

Hair, J. F., Hult, G. T. M., Ringle, C. M., \& Sarstedt, M. (2017). A Primer on Partial Least Squares Structural Equation Modeling (PLS-SEM) (2nd edition). Los Angeles: Sage.

Hendri, M. I. (2019). The mediation effect of job satisfaction and organizational commitment on the organizational learning effect of the employee performance. International Journal of Productivity and Performance Management, 68(7), 1208-1234.

Jain, A. K., \& Moreno, A. (2015). Organizational learning, knowledge management practices and firm's performance: An empirical study of a heavy engineering firm in India. Learning Organization, 22(1), 14-39.

Jarvis, C. B., MacKenzie, S. B., \& Podsakoff, P. M. (2003). A Critical Review of Construct Indicators and Measurement Model Misspecification in Marketing and Consumer Research. Journal of Consumer Research, 30(2), 199-218.

Kementerian Perencanaan Pembangunan Nasional/Badan Perencanaan Pembangunan Nasional. (2019). Rencana Pembangunan Jangka Menengah Nasional 2020-2024: Indonesia Berpenghasilan Menengah - Tinggi yang Sejahtera, Adil, dan Berkesinambungan. Kementerian PPN/Bappenas. Jakarta.

Khandekar, A., \& Sharma, A. (2006). Organizational learning and performance: Understanding Indian scenario in present global context. Education and Training, 48(89), 682-692.

Limpanitgul, T., Boonchoo, P., Kulviseachana, S., \& Photiyarach, S. (2017). The relationship between empowerment and the three-component model of organisational commitment: an empirical study of Thai employees working in Thai and American airlines. International Journal of Culture, Tourism, and Hospitality Research, 11(2), 227-242.

Nawawi, M. T. (2015). Pengaruh Kepuasan Kerja, Dan Motivasi Kerja Terhadap Kinerja Karyawan/ti Dengan Komitmen Organisasional Sebagai Variabel Intervening (Studi 
Karyawan Outsourcing PT. J Yang Ditempatkan Di Kampus II Untar Jakarta). Jurnal Manajemen Dan Bisnis Indonesia, 3(1), 129-147.

Oh, S. Y. (2019). Effects of organizational learning on performance: the moderating roles of trust in leaders and organizational justice. Journal of Knowledge Management, 23(2), $313-331$.

Pham, L. T., \& Hoang, H. V. (2019). The relationship between organizational learning capability and business performance. Journal of Economics and Development, 21(2), 259-269.

Pool, S., \& Pool, B. (2007). A management development model: Measuring organizational commitment and its impact on job satisfaction among executives in a learning organization. Journal of Management Development, 26(4), 353-369.

Rashid, M. Z. A., Sambasivan, M., \& Johari, J. (2003). The influence of corporate culture and organisational commitment on performance. Journal of Management Development, 22(7-8), 708-728.

Ringle, C. M., Silva, D., \& Bido, D. S. (2014). Structural Equation Modeling with the Smartpls. REMark - Revista Brasileira de Marketing.

Robbins, S. P., \& Coulter, M. (2010). Management (11th ed.). New Jersey: Pearson Education.

Sanusi, A. (2011). Metodologi Penelitian Bisnis. Jakarta : Penerbit Salemba Empat.

Saranya, K. (2014). Influence of Job Satisfaction on Employees' Performance-A general Perspective. International Journal on Global Business Management \& Research, 2(2), 48.

Siengthai, S., \& Pila-Ngarm, P. (2016). The interaction effect of job redesign and job satisfaction on employee performance. Evidence-Based HRM, 4(2), 162-180.

Šikýr̆, M. (2011). Determinants of Employee Performance: How To Achieve Sustained Competitive Advantage. 40-41.

Singh, J. K. (2013). A Study of Employees Job Satisfaction and Its Impact on their Performance. Journal of Indian Research.

Suliman, A. M. T. (2001). Work performance: Is it one thing or many things? The multidimensionality of performance in a Middle Eastern context. International Journal of Human Resource Management.

Suliman, A., \& Kathairi, M. Al. (2013). Organizational justice, commitment and performance in developing countries: The case of the UAE. Employee Relations, 35(1), 98-115.

Yılmaz, S. M., Çelebi, Ç. D., \& Çakmak, E. (2014). Job Satisfaction Level of Academicians in Faculty of Education. Procedia - Social and Behavioral Sciences, 116, 1021-1025. 